
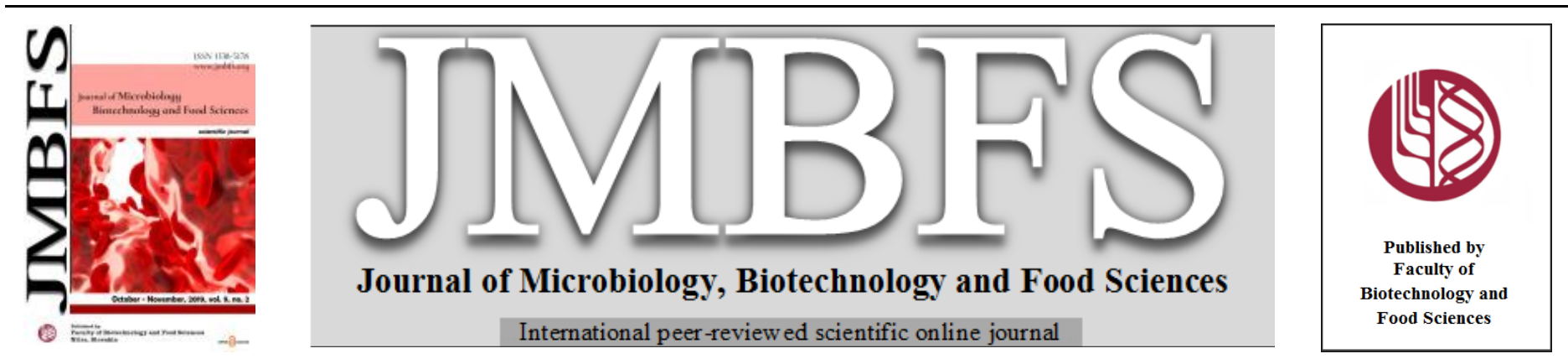

\title{
EFFECTS OF DEHYDRATION ON THE PHYSIOCHEMICAL CHARACTERISTICS OF TOMATO, ONION AND PEPPER POWDERED CULINARY BLENDS
}

\author{
Ogori A. $F^{l}$, Amove $J^{1, *}$, Adoba J. $A^{2}$, Lukas Hleba ${ }^{3}$, Miroslava Císarová ${ }^{4}$, Alexey Glinushkin ${ }^{5,6,7}$, Alexey Laishevtcev ${ }^{8,9}$, Anna \\ Derkanosova $^{10}$, Pigorev Igor ${ }^{11}$, Sergey Plygun ${ }^{9,12,13}$, Mohammad Ali Shariati ${ }^{9}$
}

\section{Address(es):}

${ }^{1}$ Department of Food Science and Technology, Federal University of Agriculture, Makurdi, Benue State, Nigeria.

${ }^{2}$ Department of Home Science, Faculty of Agriculture, Federal University, Gashua, Gashua, Yobe State, Nigeria.

${ }^{3}$ Department of Microbiology, Faculty of Biotechnology and Food Sciences, Slovak University of Agriculture in Nitra, Nitra, Slovak Republic.

${ }^{4}$ University of SS. Cyril and Methodius, Department of Biology, Faculty of Natural Sciences, Nám. J. Herdu 2, SK-91701 Trnava, Slovak Republic.

${ }^{5}$ Doctor of Agricultural Sciences, Head of Department of Resistance Studies, All Russian Research Institute of Phytopathology, Moscow Region, Russia.

${ }^{6}$ Professor of the Russian Academy of Sciences, Moscow, Russia.

${ }^{7}$ Professor, Orenburg State Agrarian University, Orenburg, Russia.

${ }^{8}$ Senior Researcher, Federal Research Center - All-Russian Scientific Research Institute of Experimental Veterinary Medicine named after K.I. Skryabin and Y.R. Kovalenko of the Russian Academy of Sciences, Moscow, 109428, Russia.

${ }^{9}$ Laboratory of Biological Control and Antimicrobial Resistance, Orel State University named after I.S. Turgenev, Orel City, 302026, Russia.

${ }^{10}$ Candidate of Technical Sciences, Associate Professor, Department of service and restaurant business, Voronezh state university of engineering technologies, Voronezh, 394036, Russia.

${ }^{11}$ Professor, Vice Rector on Science, Kursk State Agricultural Academy, Kursk, 305021, Russia.

${ }^{12}$ European Society of Clinical Microbiology and Infectious Diseases, Basel, 4051, Switzerland.

${ }^{13}$ All Russian Research Institute of Phytopathology, Moscow Region, 143050, Russia.

*Corresponding author: ninakelechiolo22@gmail.com, shariatymohammadali@gmail.com

doi: 10.15414/jmbfs.2020.9.5.994-997

\section{ARTICLE INFO}

Received 10.7. 2019

Revised 23. 10. 2019

Accepted 20. 11. 2019

Published 1. 4. 2020

Regular article

OPEN $\partial_{\text {ACCESS }}$

\section{ABSTRACT}

Quality evaluation of blends of tomato, onion and pepper powder were studied using standard methods. Blends of tomato, onion and pepper were formulated at different ratio. Sample A (TOP100/0/0), sample B (TOP 70/25/5), Sample C (TOP 70/20/10), sample D TOP70/15/15 and Sample E (TOP 70/10/20). The functional chemical and sensory properties of the sample were evaluated. Result showed decrease in moisture content from $11.70-9.15 \%$ as the ration of the onion and pepper varies, also wettability of the sample decreases as the ration of onion and pepper were alternated from $2.5-2.00 \mathrm{~g} / \mathrm{ml}$ but density of samples increases from $0.80-0.78 \mathrm{~g} / \mathrm{ml}$, reconstitution index shows that sample A has the highest value of $8.95 \mathrm{~g} / \mathrm{ml}$ while sample D has the least value of $6.00 \mathrm{~g} / \mathrm{ml}$, water absorption capacity of sample B has the highest oil absorption capacity value of $2.10 \%$ while sample B and E has the least oil absorption capacity of $1.61 \%$.Vitamin $\mathrm{C}$ content of sample increases as the ration of onion and pepper were varied with sample $\mathrm{E}$ having the highest value of $16.06 \mathrm{mg} / 100 \mathrm{~g}$ while sample A has the least value of $11.25 \mathrm{mg} / 100 \mathrm{~g} \mathrm{PH}$ of sample decreases with sample E having the highest value of 7.20 while sample A has the least value of 6.95 . Sensory evaluation scores of the sample indicates that all sample were moderately liked based on appearance, aroma, taste and overall acceptability. Based on the functional, chemical and sensory properties sample $\mathrm{E}$ is preferred.

Keywords: Tomato, Onion, Pepper, Blend, Chemical and Functional Propertie

\section{INTRODUCTION}

Drying is a process in which water is removed to halt or slow down the growth of spoilage microorganisms, as well triggers certain chemical reactions. Dehydration of foods has removed moisture content to less than $2.5 \%$ water $\%$ dry basis) unlike dried foods with more than $2.5 \%$ water \%dry basis) (VegaMercado et at., 2001). However, drying decreases the water content of the raw product to levels that minimizes its biochemical, chemical and micro-biological deterioration (Owureku-Asure, et al., 2014). Dehydrated vegetable and fruit powders has a longer shelf life and some are packed with essential vitamins and minerals to improve their bio-accessibility. Powdered vegetable and fruits are high in demand, but limited by bland flavors and washed out colors caused by poor extraction, processing and storage technology.

Tomatoes (Solanumlycoperscicum) is one of the most widely used and versatile vegetable crops. They are consumed fresh and are also used to manufacture a wide range of processed products (Ray et al., 2016; Santos de souse et al., 2008). However, limited by seasonality and post-harvest losses, and sometimes to total waste (Srivastara and Kulshreshtha, 2013). Processing dehydrated tomato and its product depends certain thermodynamic and functional properties. (OwurekuAsure, et al., 2014).
Peppers (hot and sweet) belong to the Solanaceae family, genus Capsicum.). Red pepper is generally known to be cholesterol free, and have low sodium and caloric contents, and serve as good source of vitamins A and C. In food processing, red pepper is also used as coloring and flavoring agent in sauces, soups, pickles, and pizzas.

Like other fresh fruits and vegetables, fresh pepper is a perishable produce and deteriorates within a few days after harvest without proper storage or preservation measures. The perishable nature of pepper can lead to economic losses which are further aggravated by storage and marketing problems and lack of appropriate processing technologies. The major goal in drying fruits and vegetables such as pepper is to reduce the moisture content of desirable levels, usually $5-10 \%$, which allows for safe storage over an extended period of time (Owusu-Kwarteng, et al., 2017).

Onion, one of the main 'bulbs' of Allium family, is the most commonly used spice in the cuisine and culinary preparations in tropical countries. Onion helps to prevent several diseases such as cancer, tumor cataract, cardiovascular, asthma, ulcer. It is also used as antimicrobial and anti-agitating agents and antioxidant (Mitra et al., 2011).

Vegetables are good sources of micronutrients for humans although its production is limited due to season and regional variations and due to it high 
moisture content it is highly perishable there by limiting its storage life and transportation. It is therefore necessary to process vegetables into dehydrated form to prolong shelf life and ease transportation, easily reconstitution, save time and cut off inconveniences during culinary operations. The focus of this work is to determine the physiochemical and functional properties of these powdered blends for food applications.

\section{MATERIAL AND METHODS}

Fresh onions, peppere and tomatoes were purchased from Wurukum Market, Makurdi; local packaging materials were purchased from north bank market, Makurdi Benue State.

\section{Methodology}

Sample Preparation

Fresh tomatoes, onions and pepper were sorted and washed in clean water and were cut into slices of $5 \mathrm{~mm}$ thickness using sharp stainless steel knife.

\section{Pre-treatment Prior to dehydration Process}

The sliced onions were dipped into solution of 0.2 per cent NaMS( sodium metabisulphite( solution for 5 minutes at room temperature (Sangwa et al., 2010), the sliced tomatoes were dipped in salt solution $(0.2 \% \mathrm{NaMS})$ for 10 minutes at room temperature (Ladi et al., 2017; Sarker et al., 2014), and $0.1 \%$ $\mathrm{NaMS}+0.1 \% \mathrm{CaCl}$ were used to treat matured red pepper.

\section{Dehydration Processes}

To get a uniform product, the tomato, onion and pepper sliced were placed singly in layers on trays for dying in hot air oven at predetermined temperatures of $60^{\circ} \mathrm{C}$ and dried to constant weight for 24 hours. Finally dried tomato, onions and pepper slices were weighed, milled and blended together based on the blend formulation. The powdered samples were preserved inside desiccators to preven re-absorption of moisture and packed in polythene bag for analysis and stored in dry place for determination of different functional and sensory properties. The detailed procedure of drying is given in Figure 1.

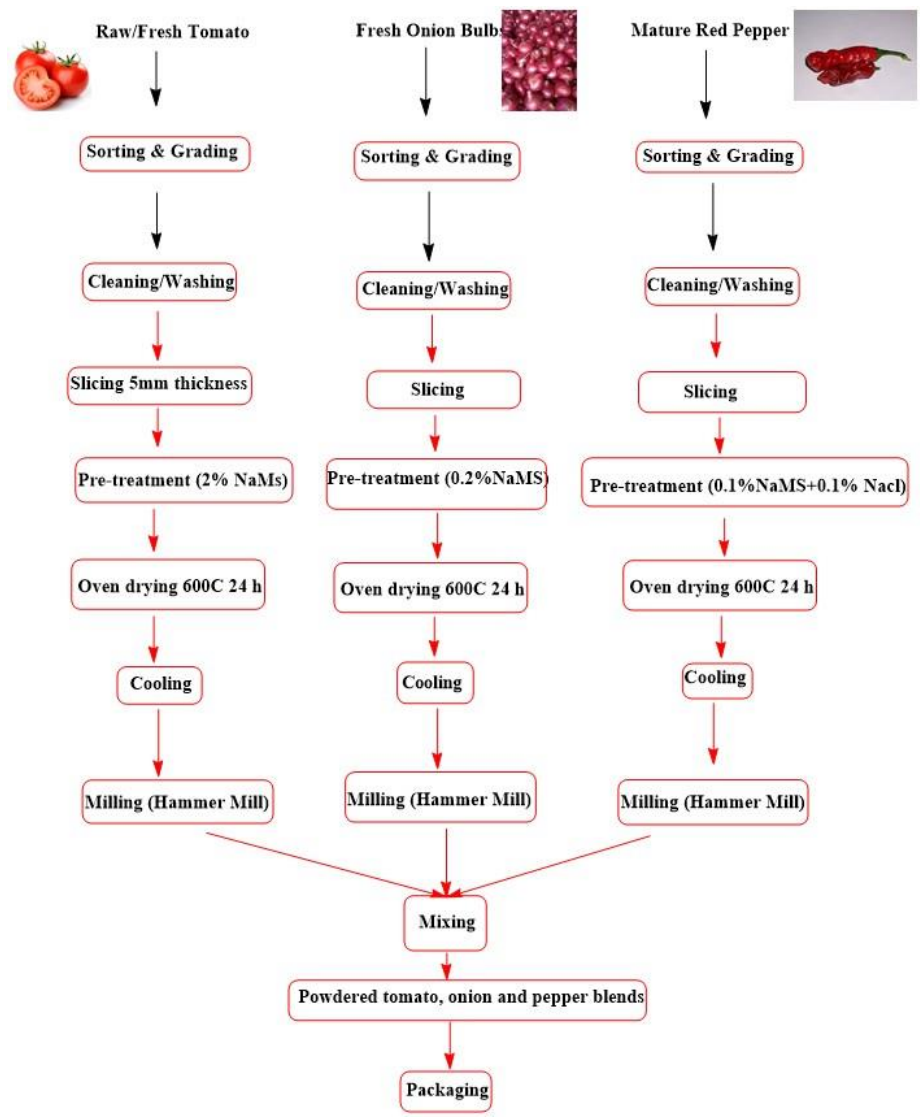

Figure 1 Flow chart for the production of powdered tomato onion and pepper blends (Sangwan et al., 2010; Ladi et al., 2017; and Sarker et al., 2014).
Table 1 Blends Formulation

\begin{tabular}{llll} 
Samples & Tomato $\%$ & Onion $\%$ & Pepper \% \\
\hline A & 100 & 0 & 0 \\
B & 70 & 25 & 5 \\
C & 70 & 20 & 10 \\
D & 70 & 15 & 15 \\
E & 70 & 10 & 20
\end{tabular}

\section{Functional Properties}

\section{Determination of Bulk Density}

$50 \mathrm{~g}$ flour sample was put into a $100 \mathrm{ml}$ measuring. The cylinder was tapped several times on a laboratory bench to a constant volume. The volume of sample was recorded.

$$
\text { Bulk density }(\mathrm{g} / \mathrm{cm})=\frac{\text { Weight of S Ample }}{\text { Volume of Sample After Tappng }}
$$

\section{Water and oil absorption capacity}

This was determined using the method of Lin et al. (1974). One gram of the sample was dispensed into a weighed centrifuge tube with $10 \mathrm{ml}$ of distilled water and mixed thoroughly. The mixture was allowed to stand for 1 hour before being centrifuged at 3500rpm for 30 minutes. The excess water (unabsorbed) was decanted and the tube inverted over an adsorbent paper to drain dry. The weight of water absorbed was determined by difference. The water absorption capacity was calculated as:

$$
\text { WAC\% }=\frac{\text { Volume of water used-Volume of free water }}{\text { Weight of sample used }} \times \frac{100}{1}
$$

\section{Wettability and Sinkability}

Wettability and sinkability of powders are difficult to separate and they were done in one test. The test was started by spreading five grams of air dried tomato powder on the surface of a filter paper, held tightly between the gaps of two small food cans (just enough to pull) where the cans were opened at both ends. The assembly of the two cans and the filter paper were mounted on glass beaker (500 $\mathrm{ml}$ ) containing $500 \mathrm{ml}$ distilled water, paring in mind; the height of the surface of the beaker and end of the apparatus is 3 inches. They were left to immerse and then; the time for the powder to be wetted was recorded, on the other hand time taken by the powder to sink down was also recorded (Sulieman et al., 2013).

\section{Reconstitution Index}

The reconstitution index of the sample was determined according to method described by Onwuka et al. (2005). Five grams of the sample was dissolved in $50 \mathrm{ml}$ of boiling water. The mixture was agitated for 90 seconds and was transferred into a $50 \mathrm{ml}$ graduated cylinder and the volume of the sediment was recorded after setting for 30 minutes.

$$
\mathrm{RI}(\mathrm{g} / \mathrm{ml})=\frac{\text { Volume of sediment }}{\text { Weight of Sample }}
$$

\section{Chemical Composition}

\section{Determination of Vitamin C}

Vitamin C was determined using the method described by AOAC (2012). $10 \mathrm{~g}$ of the sample was weighed into $250 \mathrm{ml}$ flask and $50 \mathrm{ml}$ acetone was filtered. The filtrate was meastured and equal volume of saturated $\mathrm{NaCl}$ was added to wash the filtrate. The mixture was shaken then transferred to a separating funnel and the layer of the filtrate was removed. The upper layer was washed again with $100 \%$ Potassium trioxocarbonate (IV) (K2CO3), then separated and finally washed with about $10-20 \mathrm{ml}$ of distilled water. The absorbance was read in a spectrophotometer.

\section{Determination of Lycopene}

The low volume hexane extraction method (LVHEM) was performed as in Fish et al. (2002). Approximately 0.6 (determined to the nearest $0.01 \mathrm{~g}$ ) duplicate samples were weighed from each puree into three two $40 \mathrm{ml}$ amber screw-top vials (Fisher, \#03 - 391-9F) that contained $5 \mathrm{ml}$ of $0.05 \%(\mathrm{w} / \mathrm{v})$ butylatedhydroxytoluene (BHT) in acetone, $5 \mathrm{ml}$ of $95 \%$ USP grade ethanol, and $10 \mathrm{ml}$ of hexane. Purees were stirred on a magnetic stirring plate during sampling Samples were extracted on an orbital shaker at 180 RPM for 15 minutes of ice. Samples were extracted on an orbital added to each vial and the samples were shaken for an additional 5 minutes on ice. The vials were then left at room 
temperature for 5 minutes to allow for phase separation. The absorbance of the upper, hexane layer was measured in a $1 \mathrm{~cm}$ path length quartz cuvette at $503 \mathrm{~nm}$ blanked with hexane. The lycopene content of each sample was then estimated using the aborbance at $503 \mathrm{~nm}$ and the sample weight (Beerh and Siddappa, 1959; Fish et al., 2002).

\section{Determination of Moisture Content}

The moisture content was determined by hot air oven method as described by AOAC crucible. The samples were placed into the hot air oven and dried for 24 hours at $1000 \mathrm{C}$. The crucible and its contents were cooled in the desiccators and their weights taken. The loss in weight was regarded as moisture content and expressed as:

$$
\% \text { moisture } \frac{\text { Weight loss }}{\text { Weight of sample }} \times 100
$$

Where,

$\mathrm{W} 1$ = weight of empty dish

$\mathrm{W} 2$ = weight of dish and the weight of the sample

W3 - weight of dish and sample after drying

\section{Determination of $\mathrm{pH}$}

Five grams of sample was grounded, suspended in $50 \mathrm{ml}$ of distilled water and the solution was shaked well. After calibration of $\mathrm{pH}$ meter, $\mathrm{pH}$ values of the samples solutions were measured (Yusufe et al., 2017).

\section{Sensory Evaluation}

The blended tomato, onions and pepper samples were analyzed for taste, texture, flavour, as well as overall acceptability using a 15 - member semi-trained panel, made up of students of the University of Agriculture, Makurdi. A 9-point hedonic score system as highlighted by Sengev et al. (2015) was used with the following ratings; 9 -like extremely, $8=$ like very much, $7=$ like moderately, $4=$ like slightly, $5=$ neither like or dislike, $4=$ dislike slightly, $3=$ dislike moderately, $2=$ dislike very much and $1=$ Dislike extremely.

\section{Statistical Analysis}

The data of physio-chemical analysis was subjected to analysis of variance (ANOVA) where the Least Significant Difference (LSD) was adopted to ascertain the difference between samples. Treatment means were compared at $\mathrm{p}<0.05$.

\section{RESULTS AND DISCUSSION}

\section{Chemical Properties of Tomato, Onion and Pepper Powder Blends.}

The result of the chemical properties of tomato, onion and pepper powder blends presented in table 2. Moisture content of samples shows that sample $\mathrm{E}$ has the least moisture content of 9.15 followed by sample D 10.25 followed by sample C and B 11.20, while sample A has the highest moisture content of 11.70. The low moisture content of blends other than sample A is attributed to the addition of onion and pepper in the blends.

The vitamin $\mathrm{C}$ content ranges from 13.24 (Sample A) the lowest, 14.16 (Sample B), 14.98 (Sample C), 15.66 (Sample D), 16.12 (Sample E) the highest. The high content of vitamin $\mathrm{C}$ in the blends samples is attributed to addition of onion and pepper in the samples. According to Yusufe et al., 2017 vitamin C help the body to convert glucose in the energy.

The lycopene content of samples showed that sample A has the least lycopene content of 11.25 , followed by sample B 12.99 , followed by sample C 13.47 , followed by sample D 14.94, while sample E has the highest lycopene content of 16.06. The high rate of lycopene content is attributed to the addition of onion and pepper on the blends. According to Sousa et al. (2008) tomato and tomato products are good sources of carotenoids in particular lycopene, vitamin $\mathrm{C}$, etc. The $\mathrm{pH}$ of samples ranges from 6.92 (Sample A) the lowest, 7.15 (Sample B, C and D), 7.20 (Sample E) the highest. The high $\mathrm{pH}$ of the samples other than sample $\mathrm{A}$ is attributed to the addition of onion and pepper.

Table 2 Chemical Properties of Tomato, Onion and Pepper Powder Blends.

\begin{tabular}{lllll}
\hline Sample & & \multicolumn{3}{c}{ Parameters } \\
\hline & Moisture $(\%)$ & $\begin{array}{l}\text { Vitamin } \\
(\mathrm{mg} / 100 \mathrm{~g})\end{array}$ & $\begin{array}{l}\text { Lycopene } \\
(\mathrm{mg} / 100 \mathrm{~g})\end{array}$ & $\mathrm{pH}$ \\
$\mathrm{A}$ & $11.70 \pm 0.28 \mathrm{a}$ & $13.24 \pm 0.01 \mathrm{a}$ & $11.25 \pm 0.01 \mathrm{c}$ & $6.95 .0 .07 \mathrm{~b}$ \\
$\mathrm{~B}$ & $11.20 \pm 0.28 \mathrm{~b}$ & $14.16 \pm 0.00 \mathrm{~d}$ & $12.90 \pm 0.01 \mathrm{c}$ & $7.15 \pm 0.07 \mathrm{a}$ \\
$\mathrm{C}$ & $11.20 \pm 0.28 \mathrm{a}$ & $14.98 \pm 0.00 \mathrm{c}$ & $13.47 \pm 0.04 \mathrm{c}$ & $7.15 \pm 0.07 \mathrm{a}$ \\
$\mathrm{D}$ & $10.25 \pm 0.35 \mathrm{c}$ & $15.66 \pm 0.05 \mathrm{~b}$ & $14.94 \pm 0.01 \mathrm{~b}$ & $7.15 \pm 0.00 \mathrm{a}$ \\
$\mathrm{E}$ & $9.15 \pm 0.21 \mathrm{a}$ & $16.12 \pm 0.00 \mathrm{a}$ & $16.06 \pm 0.04 \mathrm{a}$ & $7.20 \pm 0.00 \mathrm{a}$ \\
LSD & 0.74 & 0.08 & 0.08 & 0.16 \\
\hline
\end{tabular}

Values are means \pm SD duplicate determinations

Values with different superscript within the same column are significantly different $(\mathrm{p}<0.05)$

Key:

Sample A(TOP $/ 100 / 0 / 0)=$ Tomato $100+$ Onions $0+$ Pepper 0

Sample B(TOP/70/25/5) = Tomato 70+ Onions $25+$ Pepper 5

Sample C(TOP/70/20/10) $=$ Tomato $70+$ Onions $20+$ Pepper 10

Sample D(TOP/70/15/15) = Tomato 70+ Onions $15+$ Pepper 15

Sample E $($ TOP $/ 70 / 10 / 20)=$ Tomato $70+$ Onions $10+$ Pepper 20

LSD $=$ Least Significant Difference.

The functional properties of tomato, onion and pepper powder blends presented in Table (4). Wettability of samples showed that there was no significant difference in the samples. Sample B, D and E which has he least wet ability of 2.00 followed by sample A which is control and sample $\mathrm{C}$ which has the highest wettability of 2.50 . The low wettability value of sample B, D and E is attributed to the high percentage of onions in the samples. According to Alexander et al (2008) the range of value of the wettability of powder tomato is $10.00-$ $15.00 \mathrm{~g} / \mathrm{ml}$, this is more than values found for tomato, onion and pepper powder blends this is more than the values found for tomato, onion and pepper powder blends this is attributed to the dehydration of samples and the addition of onions and pepper. Bulk density of blends ranges from 0.78 (sample D) with the least, 0.80 (samples A and B), 0.81 (samples $\mathrm{C}$ and E) the highest. The high bulk density of sample $\mathrm{C}$ and $\mathrm{E}$ is likening to low percentage of pepper in sample $\mathrm{C}$ and low onion percentage in sample E. Reconstitution index of samples showed that sample D has the least reconstitution index 6.00 followed by sample B, 6.40 followed by sample E 6.70, followed by sample C 6.85 , while sample A has the highest reconstitution index of 8.95 . The low reconstitution index of samples other than sample A is attributed to variation of onion and pepper percentage in the samples. Water absorption capacity of the blends ranges from 3.95 (sample A) the lowest, 4.15 (sample D), 3.35 (sample C), 4.55 (Sample E), 5.30 (Sample B) the highest. The low water absorption capacity of sample A is attributed to the high content of tomato in the blend. The oil absorption capacity of blends showed that sample E and B has the least oil absorption capacity of 1.61 followed by sample A 1.78 followed by sample D 1.82 while sample C has the highest oil absorption capacity of 2.17 .

Table 3 Functional Properties of the tomato, onions and pepper powder blends.

\begin{tabular}{llllll}
\hline Samples & \multicolumn{5}{c}{ Parameters } \\
\hline & WT $(\mathrm{g} / \mathrm{ml})$ & BD $(\mathrm{g} / \mathrm{ml})$ & $\mathrm{RI}(\mathrm{g} / \mathrm{ml})$ & $\mathrm{WA}(\mathrm{g} / \mathrm{ml})$ & Oil Absorption $(\%)$ \\
ATOP/70/25/5) & $2.50 \pm 0.71 \mathrm{a}$ & $0.80 \pm 0.03 \mathrm{a}$ & $8.95 \pm 0.21 \mathrm{a}$ & $3.95 \pm 0.35 \mathrm{c}$ & $1.78 \pm 0.28 \mathrm{a}$ \\
$\mathrm{BTOP} / 70 / 25 / 5)$ & $2.00 \pm 0.00 \mathrm{a}$ & $0.80 \pm 0.03 \mathrm{a}$ & $6.40 \pm 0.82 \mathrm{bcd}$ & $5.30 \pm 0.28 \mathrm{a}$ & $1.61 \pm 0.28 \mathrm{a}$ \\
CTOP/70/25/5) & $2.50 \pm 0.71 \mathrm{a}$ & $0.81 \pm 0.01 \mathrm{a}$ & $6.85 \pm 0.28 \mathrm{~d}$ & $4.35 \pm 0.35 \mathrm{c}$ & $2.17 \pm 0.21 \mathrm{a}$ \\
DTOP/70/25/5) & $2.00 \pm 0.00 \mathrm{a}$ & $0.78 \pm 0.01 \mathrm{a}$ & $6.00 \pm 0.28 \mathrm{~d}$ & $4.15 \pm 0.35 \mathrm{c}$ & $1.82 \pm 0.21 \mathrm{a}$ \\
ETOP/70/25/5) & $2.00 \pm 0.00 \mathrm{a}$ & $0.81 \pm 0.01 \mathrm{a}$ & $6.70 \pm 0.28 \mathrm{c}$ & $4.55 \pm 0.35 \mathrm{bc}$ & $1.61 \pm 0.28 \mathrm{a}$ \\
LSD & 1.15 & 0.04 & 0.066 & 0.88 & 0.66 \\
\hline
\end{tabular}

Values are means \pm SD duplicate determinations

Values with different superscript within the same column are significantly different $(\mathrm{p}<0.05)$.

Key:

Sample A TOP/70/25/5) = Tomato $100 \%+$ Onions 0\% + Pepper 0\%

Sample B TOP/70/25/5) $=$ Tomato $70 \%+$ Onions $25 \%+$ Pepper $5 \%$

Sample C TOP/70/25/5) = Tomato $70 \%+$ Onions $20 \%+$ Pepper $10 \%$

Sample D TOP/70/25/5) = Tomato $70 \%+$ Onions $15 \%+$ Pepper $15 \%$

Sample E TOP/70/25/5) $=$ Tomato $70 \%+$ Onions $10 \%+$ Pepper $20 \%$

WT $=$ Wetability

$\mathrm{BD}=$ Bulk Density

WA $=$ Water Absorption

$\mathrm{RI}=$ Recommendation Index

LSD $=$ Least Significant Difference. 


\section{Sensory Evaluation of Tomato, Onion and Pepper Powder Blends}

Result of sensory attributes of tomato, onion and pepper powder blends are presented in table 4. Sensory evaluation showed that there was no significan difference in terms of appearance, aroma, taste and overall acceptability of the samples. Sample D has the least appearance score of 7.00, followed by sample A and C 7.59, followed by sample E 7.71, while sample B has the highest score of 7.76. Aroma showed that sample D has the least score 6.76 , followed by sample E 7.29, followed by sample B 7.35, followed by sample A 7.47, while sample C has the highest score of 7.59. The taste of blends showed that sample D has the least score for taste 6.29 followed by sample E 7.00 followed by sample A 7.06 followed by sample B 7.24 while sample $C$ has the highest score in terms of taste. The overall acceptability showed that sample $\mathrm{D}$ has the least sensory score for overall acceptability followed by sample A, B and C 7.35 while sample E has the highest score of 7.53.

Table 4 Sensory Evaluation of the tomato, Onions and Pepper Powder Blends Sample

\section{Parameters}

Appearance Aroma $\quad$ Taste Overall

acceptability

$\mathrm{A}(\mathrm{TOP} / 0 / 0)$

$7.59 \mathrm{a}$

$\mathrm{B}(\mathrm{TOP} / 70 / 25 / 5) \quad 7.76 \mathrm{a}$

$7.47 \mathrm{a} \quad 7.06 \mathrm{a}$

$7.35 \mathrm{a}$

C(TOP/70/20/10) 7.59a

$7.35 \mathrm{a}$

$7.24 \mathrm{a}$

$7.35 \mathrm{a}$

D(TOP/70/15/15) 7.00

$7.59 \mathrm{a} \quad 7.35 \mathrm{a}$

$6.76 \mathrm{a}$

$6.35 \mathrm{a}-7.35 \mathrm{a}$

$\mathrm{E}(\mathrm{TOP} / 70 / 10 / 20)-7.71$

LSD

0.90

$7.29 \mathrm{a}$

$6.65 a$

$7.53 \mathrm{a}$

$\begin{array}{lll}0.86 & 1.14 & 0.96\end{array}$

Values with different superscript within the same column are significantly different $(\mathrm{p}<0.05)$

Key:

Sample A TOP $/ 100 / 0 / 0)=$ Tomato $100+$ Onions $0+$ Pepper 0

Sample B TOP $/ 70 / 25 / 5)=$ Tomato $70+$ Onions $25+$ Pepper 5

Sample C TOP/70/20/10) $=$ Tomato $70+$ Onions $20+$ Pepper 10

Sample D TOP/70/15/15) $=$ Tomato $70+$ Onions $15+$ Pepper 15

Sample E TOP/70/10/20) $=$ Tomato $70+$ Onions $10+$ Pepper 20

LSD $=$ Least Significant Difference.

\section{CONCLUSIONS}

The quality characteristics of tomato, onions and pepper powder blends was determined. Result of the study showed that, functional properties of tomato, onion and pepper powder blends were evaluated and sample E (Tomato 70+ Onions 10+ Pepper 20) was recorded to have highest values for functional properties among the samples making it the best sample for this study. Based on the chemical properties of powder blends determined, sample E have high level of vitamin $\mathrm{C}$ and lycopene content. Based on the sensory evaluation carried out on the tomato, onions and pepper blends, sample E having good sensory attributes is most preferred.

Consent: Written consent was obtained from all participants prior to interview. All information obtained in the study was stored confidential.

Conflicts of Interest: The authors declare that they have no conflicts of interest

\section{REFRENCES}

Abadio, F. D. B., Domingues, A. M., Borges, S. V. and Oliveira, V. A. and Oliveira, V.A. (2004). Physical properties of powdered pineapple (Ananascomosus) juice-effect of malt dextrin concentration and atomization speed. Journal of Food Engineering, 64; 285-287.

Abasi, S., Mousavi, S. M. Mohebi, M. and Kiani, S. (2009). Effect of Time and Temperature on moisture content, shrinkage, and rehydration of dried onion. Iranian Journal of Chemical Engineering, 6(3): 78 - 82.

Ade-Omowaye, B.I.O. Rastogi, N.K. Angersbach, A. and Knorr, D. (2002). Osmotic Dehydration of Bell peppers: Influence of high intensity electric field pulses and elevated temperature treatment. J. Food Eng, 54:35-43.

Akpinar, E. K. Bicer, Y. and Yildiz, C. (2003). Thin Layer Drying of Red Pepper. J. Food Eng, 59, 99:104.

Alejandra, M., Rojas, G., Gemma, O., Robert, S.F. and Martin-Belloso, O. (2009). The use of packaging techniques to maintain freshness in fresh-cut fruits and vegetables. Int. J. Food Sci. Tech., 44: 875-889.

Auguelova, T. and Warthsen, J. (2000). Lycopene stability in tomato powders Journal of Food Science 65: 67-70.

Araujo, J.C. and Telhado, F.P. (2015). Organic Food: A comparative Study of the effect of tomato cultivars and cultivation conditions on the physic-chemical properties. Journal of Foods Science, 4: 263-270.

Arshad, M. S. Sohalb, M., Nadeem, M., Saeed, F., Imran, A., Jaed, A., Amjad, Z. and Batool, S.M. (2017). Status and trends of nutraceuticals from onion and onion by-products: A Critical Renew. Arshad et a.., Cogent Food \& Agriculture,3: 234-244.
Arsland, D. \& Ozcan, M.M. (2011). Dehydration of red bell-pepper (Capsicum annuum L): Change in drying behavior, colour and antioxidant content. Food Bioproducts Process, 89,504-513.

Basher, N., Bhat, M.A, Dar, B.N. \& Shad, M.A. (2014). Effect of Different drying methods on the quality of tomatoes. Advances in Food Science, 36(2): 2127.

Canine-Adams, K., Clinton, S.K., King, J.L., Lindshield, B.L., Wharton, C., Jeffery, E. \& Erdman, J.W. (2004). The growth of the dunning R-3327-H transplantablkeprostateadenocarcinoma in ratsfed diets containing tomato, broccoli, lycopene, or receiving finasteride treatment. FASEB Journal, 18(8), 8691.

Catalano, P., Fucci, F., Giametta, F., Penna, A.L. \& Fianza, G.L. (2013) Experimental System and tests to optimize a tomato drying process. The Open Agriculture Journal, 7, 73-79.

Chan, A. (2016). Drying technology research for vegetable powder production: retrieved from https://www.linkedin.com/pulse/drying-technology-researchvegetable-powder.

AOAC (2012). Official Methods of Analysis. 18th Ed. American Association of Analytical Chemists, Inc., Washington.

Bamishaiye, E. I. \& Bamishaiye, O.M. (2011). Tiger nut: as a plant, its derivatives and benefits. African journal of Food Agriculture, Nutrition and Development, 11(5). https://doi.org/10.4314/ajfand.v11i5.70443.

Benchamaporn, P., Duangkhae, K. \& Sophon, B. (2009). Effect of Addition of Antioxidants on the Oxidative Stability of Refined Bleached and Deodorized Palm Olein. Kasetsart Journal of Natural Science, 43, 370 - 377.

Ezebor, F., Igwe, C.C., Owolabi, F.A.T. \& Okoh, S.O. (2005).Comparison of the physic-Chemical Characteristics,oxidative and hydrolytic stabilities of oil and fat of cyperus esculentus L. and butyrospermum parkii ( shea nut ) from Middle-Belt States of Nigeria. Nigerian Food Journal, 23, 3339. https://doi.org/10.4314/nifoj.v23i1.33596.

FAO. (1988). Traditional Food Plants: Food and Nutrition Paper 42 Rome 239. 242.

Moore M. (2004) Documents Prepared for Bottlegreen for the Product Tiger White: www.tigerwhitedrinks.com Copyright Miam Ltd. 1-22.

Nadeem, M., Abdullah, M., Hussain, I., Inayat, S., Javid, A. \& Zahoor, Y. (2013). Antioxidant Potential of Moringa oleifera Leaf Extract for the Stabilisation of Butter at Refrigeration Temperature. Czech Journal of Food Science, 31, 332-339. https://doi.org/10.17221/366/2012-cjfs .

Ndubuisi, L. C. (2009). Evaluation of food potentials of tiger nut tubers (cyperus esculentus) and its products (milk, coffee and wine).. Department of home science, nutrition and dietetics, university of nigeria, nsukka. Theses N.O. PG/M.SC/03/34134.

Olagunju, A.O. (2006). Extraction and characterization of oil from tiger nut seed (Cyperus esculentus) using 23 full factorial design. M. Sc. Thesis, Dep. of Chemical Engineering, Federal Univ. of Technology, Minna, Niger State, Nigeria.

Okafor, J. N. C., Mordi, J .I., Ozumba, A. U., Solomon, H.M. \& Olatunji, O. (2003). Preliminary studies on the characterization of contaminants in tiger nut (Yellow variety). In Proceedings of 27th annual Nigerian Institute of Food Science and Technology (NIFST) conference, 210-211.

Sadoudi, R., \& Ali Ahmed, D. (2017). Studies on physico-chemical characteristics and fatty acid composition of commercially available Algerian frying edible oils. Agriculture Department, Faculty of Biology and Agriculture, "Mouloud Mammeri" University of Tizi-Ouzou, 15000, Algeria. International Food Research Journal, 24(1): 60-67.

Shaker, M. A., Ahmed, M. Gaafar, Amany, M. B, \& Shereen, L. N. (2009). Chufa Tubers (Cyperus esculentus L.): As a New Source. World Applied Sciences Journal, 7(2), 151-156.

TTSL. (2005). Tigernuts. Chufas. Souchet. Ermandeln. Pois Sucrés: Tigernut Traders, S.L. Export. www.tigernut.com ; http:// www.tigernut.com/product3.htm 